\title{
Children and bicycles: what is really happening? Studies of fatal and non-fatal bicycle injury
}

\author{
Caroline HC Acton, Steven Thomas, James W Nixon, Ronald Clark, W Robert Pitt, \\ Diana Battistutta
}

Royal Children's Hospital, Herston, Queensland, Australia, Department of Oral and Maxillofacial Surgery, Department of Child Health CHC Acton

Department of Accident and Emergency and Outpatients R Clark

Epidemiology Unit, Queensland Institute Queensland Institute Herston, Queensland, Australia and University of Wales College of Medicine, Department of Oral Surgery, Medicine and Pathology, Cardiff, UK

$S$ Thomas

Epidemiology Unit, Queensland Institute of Medical Research Herston, Queensland, Australia

D Battistutta

Department of Child Health, University of Queensland, Herston, Queensland, Australia JW Nixon

Accident and

Emergency

Department and

Outpatients, Mater

Children's Hospital,

South Brisbane,

Queensland, Australia WR Pitt

Correspondence and reprint requests to: $\mathrm{Dr}$ CHC Acton requests to: Dr Child Health, Royal Children's Hospital, Herston, Queensland 4029, Australia.

\begin{abstract}
Objectives-The objectives of the study were to ascertain the causes of accidents, injuries, and deaths in children who ride bicycles. Fatality and injury rates were also studied in order to compare with other studies.
\end{abstract}

Methods-Two studies of children were undertaken in children aged less than 15 years. In the first (retrospective fatality study), children who died as a result of a bicycle incident during the period 198192 were reviewed. In the second (prospective injury study) data were obtained prospectively between April 1991 and June 1992 about children who were injured while riding a bicycle and treated at a public hospital in Brisbane.

Results-Study 1: fatality rates for boys were twice those for girls. The rate was highest for boys of 14 years in the metropolitan area at $6 \cdot 23 / 100000$. All deaths involved vehicles, and the majority involved head injury or multiple injuries including head injury. Study 2: similar numbers of children were injured at onroad and off-road locations. Faulty riding was described by the rider or caregiver as the cause in $62.5 \%$ of cases. The most common time of injury was between 3 and $6 \mathrm{pm}$ on both school and non-school days. Only $5.5 \%$ of all incidents involved a moving vehicle.

Conclusions-Bicycle riding by children is a common cause of injury, particularly for boys. Equal numbers of injuries occurred on the road as at other locations. Faulty riding caused most accidents. Injury prevention for bicycle riders should involve not only compulsory wearing of helmets, but should also include education and training about safe riding habits, separation of motorised vehicles from bicycles, modified helmet design to incorporate facial protection, and improved handlebar design.

(Injury Prevention 1995; 1: 86-91)

Keywords: bicycles, education, mortality, epidemiology.

Although cycling is an activity enjoyed by many children, it can be hazardous. It has been reported to be the second most common reason for injury attendance by boys in the 5-14 year age group at some hospital departments. ${ }^{1}$

Bicycle related head injury has been well documented, and there is good evidence of the reduced risk of head injury when wearing an approved safety helmet. ${ }^{23}$ However, injuries other than to the head have not received such detailed attention. Although the most serious bicycle injuries occur on public roads, serious injuries to cyclists also occur at off-road locations such as footpaths, bicycle paths, and driveways. ${ }^{45}$

The purpose of the Brisbane Bicycle Study was to examine the complete spectrum of fatal and non-fatal injuries suffered by children on bicycles, whether on or off the road, with the goal of identifying strategies to prevent or reduce these injuries.

\section{Methods}

We undertook two studies of children injured while riding bicycles.

\section{STUDY 1: A 12 YEAR RETROSPECTIVE} FATALITY STUDY (1981-92)

Data were obtained for all children aged 14 years and younger who died as a result of injuries received while bicycling during the years 1981-92 inclusive, in the State of Queensland (including Brisbane, the capital city), Australia. These were retrieved from coroner's and pathology reports, and checked against records of fatalities kept by the Queensland Transport Department to ensure complete ascertainment.

STUDY 2: A PROSPECTIVE NON-FATAL INJURY STUDY (1991-2)

Injury data were obtained for emergency department attendances and admissions to Brisbane hospitals. Most children attending emergency departments in Brisbane are seen at the two children's hospitals and the three district general hospitals that have mixed adult and paediatric facilities. Independent checks of emergency department workbooks showed we achieved in excess of $90 \%$ ascertainment of children attending Brisbane public hospitals. Case ascertainment was maximised through ward visits, systematic collection of Queensland Injury Surveillance and Prevention Project data, and by computer searches of hospital records.

Children were included in the study if they were less than 15 years of age (the cut off age for admission to our children's hospitals is 14 years) and were injured in an incident involving a bicycle, as a rider or pillion passenger, between April 1991 and June 1992. Helmet wearing was made compulsory for all riders in 
Queensland from 1 July 1991. Children were excluded from the study if their cycle had trainer wheels or was a tricycle.

The caregiver and attending doctor completed a questionnaire when the child presented to the emergency department. The questionnaire ascertained demographic data, circumstances surrounding the incident, injuries sustained, time and date of the incident, details of helmet wearing, and whether the child was supervised by an adult who had the child in sight at the time of the incident. The severity of the incident was assessed by the degree of damage to the bicycle. ${ }^{2}$ For the purpose of this study 'on-road' was defined as public roadways used by vehicular traffic. Other sites were defined as 'off-road' and included footpaths, bicycle paths, back yards, or driveways and parks. A Glasgow coma score was recorded for those children who suffered injuries to the head or face, and a paediatric trauma score was calculated for all children admitted to hospital. ${ }^{67}$ The paediatric trauma score assesses injury severity based on the child's weight, airway, blood pressure, level of consciousness, and the presence of open wounds and fractures. Possible scores range from -6 to +12 . Children with a paediatric trauma score of 6 or below have increased mortality and morbidity. ${ }^{7}$

Brisbane is a subtropical city of 1.3 million people and is the capital of Queensland, Australia. Queensland has an area of $1730330 \mathrm{~km}^{2}$ and a population of 2.6 million people.

\section{STATISTICAL METHODS}

Fatality rates were calculated using the Australian Bureau and Statistics 1986 Census of Population and Housing. The census took place at the midpoint of the fatality study and there were 620574 children aged 14 years or less in Queensland. Age adjusted fatality rates were calculated using direct standardisation to the total population aged $0-14$ in Queensland. ${ }^{8}$

The prospective study used population figures from the 1991 Brisbane census to calculate injury rates. There were 295709 children 14 years of age or less in Brisbane in $1991 .^{8}$ Age adjusted non-fatal injury rates were calculated as above.

Associations between variables describing aspects of bicycle injuries, for example whether the child was riding on the road or off it, were tested for statistical significance using $\chi^{2}$ tests of association. A $\chi^{2}$ goodness of fit test was used to determine secular trends.

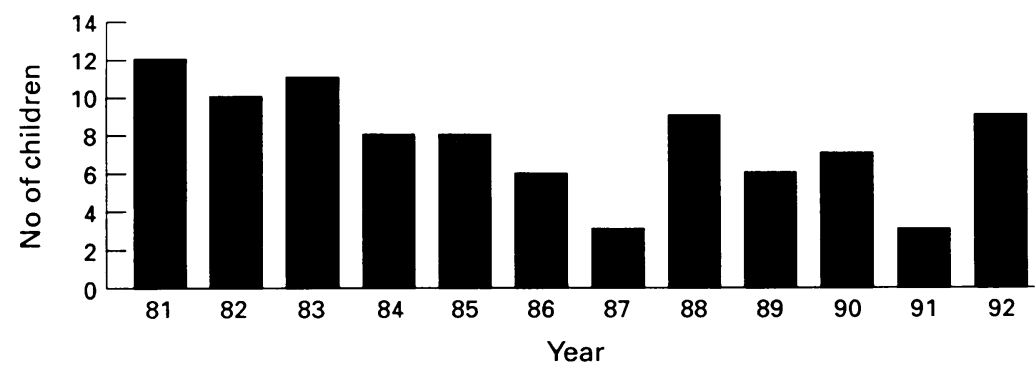

Figure 1 Children fatally injured in bicycle incidents, Queensland, Australia, by year.

\section{Results}

STUDY 1: A 12 YEAR RETROSPECTIVE

FATALITY STUDY (1981-92)

Rates

Ninety two children ( 67 boys and 25 girls) died in Queensland from bicycle related injuries from 1981 to 1992 . The fatality rates for each of these years is shown in figure 1 and show no significant secular trend $\left(\chi^{2}=11 \cdot 7, \mathrm{df}=11\right.$, $\mathrm{p}=0.39)$. The average annual fatality rates (age adjusted) for boy $0-14$ was $1 \cdot 8 / 100000$ and for girls was $0 \cdot 7 / 100000$. The boy:girl rate ratio was $2.64\left(95^{\circ}\right.$ o confidence interval) $(\mathrm{CI})$ $1 \cdot 66$ to $4 \cdot 21)$.

The average annual age adjusted fatality rates/100000 children for Queensland are shown in table 1 . Table 2 shows average annual age adjusted fatality rates for the same area of Brisbane included in the prospective 14 month injury study. Forty children ( 30 boys and 10 girls) died over the 12 year period in Brisbane. The sex rate ratio was $3.27(95 \%$ CI 1.56 to $6 \cdot 8)$.

\section{Causes of accidents}

All of the fatal bicycle related injuries involved vehicles (including one train and three motor cycles) and all but three occurred on the road.

Table 1 Annual age specific and age adjusted fatal bicycle injury rates 100000 children aged $0-14$ years in Queensland 1981-92*

\begin{tabular}{llll}
\hline $\begin{array}{l}\text { Age } \\
\text { (years) }\end{array}$ & Boys & Girls & $\begin{array}{l}\text { Both } \\
\text { sexes }\end{array}$ \\
\hline 0 & 0.00 & 0.00 & 0.00 \\
2 & 0.00 & 0.00 & 0.00 \\
3 & 0.00 & 0.00 & 0.00 \\
4 & 0.00 & 0.00 & 0.00 \\
5 & 1.21 & 0.43 & 0.84 \\
6 & 2.50 & 1.33 & 1.93 \\
7 & 1.24 & 0.88 & 1.07 \\
8 & 2.06 & 0.43 & 1.27 \\
9 & 2.46 & 0.85 & 1.67 \\
10 & 2.78 & 1.26 & 2.04 \\
11 & 2.68 & 0.81 & 1.77 \\
12 & 3.67 & 1.55 & 2.64 \\
13 & 1.77 & 0.74 & 1.26 \\
14 & 5.09 & 1.43 & 3.31 \\
Total & & & \\
Crude & 1.750 & 0.691 & 1.235 \\
Age adjusted & 1.753 & 0.663 & - \\
\hline
\end{tabular}

^Based on the 1986 census of population and housing.

Table 2 Age specific and age adjusted fatal bicycle injury rates 100000 children aged $0-14$ years in the Brisbane Statistical Division 1981-92^

\begin{tabular}{|c|c|c|c|}
\hline $\begin{array}{l}\text { Age } \\
\text { (years) }\end{array}$ & Boys & Girls & $\begin{array}{l}\text { Both } \\
\text { sexes }\end{array}$ \\
\hline 0 & 0.00 & 0.00 & $0 \cdot 00$ \\
\hline 1 & 0.00 & 0.00 & $0 \cdot 00$ \\
\hline 2 & 0.00 & 0.00 & 0.00 \\
\hline 3 & 0.00 & 0.00 & $0 \cdot 00$ \\
\hline 4 & 0.00 & 0.00 & $0 \cdot 00$ \\
\hline 5 & 0.94 & 0.00 & 0.49 \\
\hline 6 & $2 \cdot 86$ & 2.05 & $2 \cdot 47$ \\
\hline 7 & 0.00 & 0.00 & 0.00 \\
\hline 8 & 0.95 & 0.99 & 0.97 \\
\hline 9 & $1 \cdot 88$ & 0.98 & 1.44 \\
\hline 10 & 3.67 & 0.98 & $2 \cdot 37$ \\
\hline 11 & $1 \cdot 75$ & 1.84 & $1 \cdot 79$ \\
\hline 12 & 5.05 & 0.90 & 3.04 \\
\hline 13 & $3 \cdot 24$ & $0 \cdot 83$ & $2 \cdot 05$ \\
\hline 14 & $6 \cdot 23$ & 0.00 & $3 \cdot 15$ \\
\hline \multicolumn{4}{|l|}{ Total } \\
\hline Crude & 1.873 & 0.573 & $1 \cdot 240$ \\
\hline Age adjusted & 1.878 & 0.573 & - \\
\hline
\end{tabular}

$\star$ Based on the 1986 census of population and housing. 
Causes of death

Fifty two children died from head injuries alone, 25 from multiple injuries (including head injuries), 10 from abdominal injuries, one from a haemothorax, and one had a ruptured aorta. The specific cause of death was unknown for two children.

\section{Helmet wearing}

Data on helmet wearing were reported for only six children, none of whom was wearing a helmet.

\section{STUDY 2: A PROSPECTIVE NON-FATAL INJURY} STUDY (1991-2)

Rates

The five hospital emergency departments that receive children in Brisbane, treated 813 children with bicycle related injuries during the study period -607 boys $(74.7 \%$ ) and 206 girls $(26.3 \%)$. The injury rates/100 000 children for each age cohort in single age groups are shown in table 3. The total injury rate for 1-14 year olds was $294 \cdot 7 / 100000$. As expected, boys had injury rates almost three times higher than girls $(428.5 v 153.7 / 100000$; sex rate ratio $2 \cdot 78,95 \%$ CI 2.37 to 3.26$)$. One hundred and fifty one children (18.6\%) were admitted to hospital (116 boys and 35 girls). The numbers of children injured on-road and off-road were 397 and 390, respectively. (Data were unavailable for 26 cases.) Table 4 shows the number of injured children grouped by age.

Eighty of the children (53.0\%) admitted to hospital for inpatient care were riding on-road, and 19 of these children (22.5\%) were hit by a car or truck. One child riding off-road on a footpath was hit by a car.

Table 3 Age specific and age adjusted fatal bicycle injury rates 100000 children aged $1-14$ years in the Brisbane Statistical Division ${ }^{\star}$ for the 14 months of the survey

\begin{tabular}{|c|c|c|c|c|}
\hline \multicolumn{2}{|l|}{$\begin{array}{l}\text { Age } \\
\text { (years) }\end{array}$} & Boys & Girls & $\begin{array}{l}\text { Both } \\
\text { sexes }\end{array}$ \\
\hline \multicolumn{2}{|l|}{$\begin{array}{r}1 \\
2 \\
3 \\
4 \\
5 \\
6 \\
7 \\
8 \\
9 \\
10 \\
11 \\
12 \\
13 \\
14\end{array}$} & $\begin{array}{r}20.4 \\
49.7 \\
183.5 \\
184.6 \\
231 \cdot 3 \\
317.0 \\
542.1 \\
438.5 \\
404.2 \\
481.0 \\
756.4 \\
864.8 \\
829.4 \\
631.8\end{array}$ & $\begin{array}{r}0.0 \\
42.7 \\
87.7 \\
107.8 \\
181.9 \\
167.9 \\
233.2 \\
221.1 \\
237.3 \\
239.3 \\
251.6 \\
155.6 \\
160.9 \\
58.7\end{array}$ & $\begin{array}{r}10 \cdot 4 \\
46 \cdot 3 \\
137 \cdot 4 \\
147 \cdot 2 \\
207 \cdot 4 \\
244 \cdot 6 \\
391 \cdot 8 \\
332 \cdot 7 \\
322 \cdot 6 \\
364 \cdot 8 \\
510 \cdot 6 \\
519 \cdot 8 \\
504 \cdot 0 \\
350 \cdot 4\end{array}$ \\
\hline \multicolumn{2}{|c|}{$\begin{array}{l}\text { Crude } \\
\text { Age adjusted }\end{array}$} & $\begin{array}{l}428 \cdot 2 \\
428 \cdot 5\end{array}$ & $\begin{array}{l}153 \cdot 6 \\
153 \cdot 7\end{array}$ & $294 \cdot 7$ \\
\hline \multicolumn{5}{|c|}{${ }^{\star}$ Based on the 1991 census of population and housing } \\
\hline \multicolumn{5}{|c|}{$\begin{array}{l}\text { Table } 4 \text { Site of accident and age group ( } 787 \text { child } \\
\text { cyclists, April 1991-fune 1992, Brisbane); values are } \\
\text { number }(\%)\end{array}$} \\
\hline & $\begin{array}{l}0-4 \\
\text { years }\end{array}$ & $\begin{array}{l}5-9 \\
\text { years }\end{array}$ & $\begin{array}{l}10-14 \\
\text { years }\end{array}$ & Total \\
\hline $\begin{array}{l}\text { On-road } \\
\text { Off-road }\end{array}$ & $\begin{array}{l}17(27.0) \\
46(73.0)\end{array}$ & $\begin{array}{l}122(43.0) \\
162(57.0)\end{array}$ & $\begin{array}{l}258(58.9) \\
182(41 \cdot 4)\end{array}$ & $\begin{array}{l}397 \\
390\end{array}$ \\
\hline
\end{tabular}

Days and time of day

Children were twice as likely to be injured on non-school days than on school days and the most common time of injury was between 3 and $6 \mathrm{pm}$. However, these hours accounted for $46 \%$ of injuries on non-school days compared with $75 \%$ of injuries on school days. The number of children injured declined after 6 pm (figure 2).

\section{Supervision}

Children injured while riding on the road were less likely to be supervised by an adult who could see them than children injured while riding off-road $\left(\chi^{2}=19.9, \mathrm{df}=1, \mathrm{p}=0.001\right)$.

\section{Causes of accident}

'Faulty riding' was described as the cause of the incident by 508 children $(62.5 \%)$, with no difference in frequency between riding on-road and off-road. Most of these included 'riding too fast, larking about, doing wheelies' etc. There were no accidents involving toddler seats. Seventy eight children $(9.6 \%)$ described the cause of their accident as a faulty bike; most commonly brake failure, chains coming off, and wheels loosening or coming off. The remaining causes included faulty road $(5.6 \%)$, faulty driving of another vehicle $(7 \cdot 2 \%)$, or avoiding an obstruction such as a pedestrian or animal $(8.0 \%)$. Fifty seven children $(7 \cdot 1 \%)$ did not know the cause of the incident.

\section{Causes of injury}

Impact with a motor vehicle before landing was a significant cause of injury for road users compared with off-road $\left(\chi^{2}=23 \cdot 2, \mathrm{df}=1\right.$, $\mathrm{p}<0.001)$. Other injury causes, such as the surface on which the child fell, showed no difference in frequency between on-road and off-road riders. Forty five children collided with a moving car, while two were hit by motorbikes. Children hit by a vehicle represented $8.0 \%$ of those injured riding onroad and $5.5 \%$ of all children injured in bicycle incidents. Collisions between bicycles arose

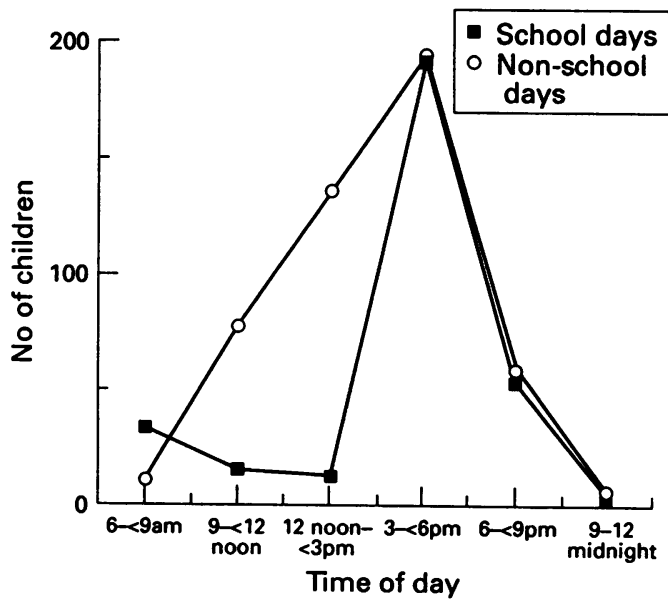

Figure 2 Children injured on school and non-school days for different time periods, April 1991-fune 1992, Brisbane. 
Table 5 Body parts injured ( 813 child cyclists, April 1991-fune 1992, Brisbane)

\begin{tabular}{lc}
\hline Body part & No $(\%)$ \\
\hline Arm & $455(34 \cdot 0)$ \\
Leg & $349(26 \cdot 0)$ \\
Face & $315(23 \cdot 5)$ \\
Head & $105(7 \cdot 8)$ \\
Trunk & $80(6 \cdot 0)$ \\
Digestive tract & $23(1 \cdot 8)$ \\
Neck & $8(0 \cdot 7)$ \\
Other & $3(0 \cdot 2)$ \\
Total & $1338(100 \cdot 0)$ \\
\hline
\end{tabular}

with similar frequency on-road and off-road. Six hundred and eighty three children $(84.0 \%)$ had no contact with a moving object, that is they just fell off their bike. One rider claimed to have fallen asleep at the handlebars! Twelve who were admitted to hospital were injured when they fell against the kerb and one half of these injuries were to the head. Other objects hit included drains, traffic islands, trees, and potholes.

\section{Severity of incident}

The incident was considered severe in 17 $(2 \cdot 1 \%)$ children, in that the bicycle was damaged beyond repair. It was in need of repair' in an additional 144 cases $(17 \cdot 7 \%)$. There were significantly more damaged bicycles among those injured on-road (107 children, 18.4\%) than among off-road riders (54 children, $9.0 \%)\left(\chi^{2}=28.6, \mathrm{df}=1, \mathrm{p}<0.001\right)$.

Weather conditions were not an important factor. Five hundred and one children (61.6\%) reported on weather conditions with only 18 $(2 \cdot 2 \%)$ saying it had been raining at the time.

\section{Injury distribution}

The body parts affected are shown in table 5 . Eight hundred and four $(60.0 \%)$ were to the limbs, $315(24.0 \%)$ to the face, and $105(8.0 \%)$ to the head. Facial injuries included seven fractures of the mid-third of the face, 16 mandibular fractures, 91 extraoral abrasions and lacerations, 14 intraoral lacerations, and 33 injuries to the teeth and gums. There was no difference in injury types to children riding on-road or off-road.

\section{Paediatric trauma score}

The paediatric trauma score ranged from -3 to +12 . There was no difference in distribution of the scores between on-road and off-road users. Of the children admitted to hospital, 19 $(12.6 \%)$ had a score of 6 or below, indicating potentially life threatening injuries. Twelve of these were riding on-road, six off-road, while in one case the location was unknown. The low paediatric trauma scores were generated by skull injuries with concomitant intracerebral injury and compound fractures of limbs.

\section{Head impact}

Two hundred and ninety four children $(36 \cdot 2 \%)$ hit their head when they fell off. One hundred and five $(12.9 \%)$ suffered some injury to the head, for example cuts and bruises while 66 $(8 \cdot 1 \%)$ had episodes of altered consciousness. Head impact was more likely in an on-road incident (165 of 321 riders) than off-road (129 of 320 riders) $\left(\chi^{2}=7 \cdot 9, \mathrm{df}=1, \mathrm{p}<0.05\right)$. Five children had a Glasgow coma score of less than 8 , indicating a severe head injury and none were wearing a helmet. In this prospective study the one child who died sustained head injuries, was riding on-road, and was not wearing a helmet.

\section{Helmet wearing}

Six hundred and eighty three children $(84.0 \%)$ said they owned an Australian Standards approved helmet, but only $330(40.5 \%)$ were wearing one at the time. ${ }^{9}$ Another $28(3.0 \%)$ were wearing non-Australian Standards approved helmets. Helmet wearing was similar in children riding on-road $(186,46.0 \%)$ and offroad $(144,37.0 \%)$. Three hundred and twenty three $(97.8 \%)$ of these helmets were of the hard shell type. ${ }^{11}$

\section{Abdominal injury}

Forty nine children suffered an abdominal injury. Of these, 21 were admitted to hospital, and 10 suffered major organ damage necessitating prolonged hospital admission. In all cases the cause was blunt trauma from the unprotected ends of handlebars. ${ }^{12}$ Twelve children suffered perineal and genital injuries, but none was considered serious. Two were admitted for genital lacerations that required suturing.

\section{Discussion}

The finding that all bicycle related fatal injuries involved motor vehicles is consistent with previous studies. ${ }^{45}$ Engineering solutions include separating bicycles from traffic, while more safety education would appear to be indicated for cyclists and motorists alike.

Fatality rates are higher for 12-14 year old boys than for any other age group. During the period of this study this group showed some resistance to wearing helmets. ${ }^{13}$ There was no sustained decrease in bicycle related fatalities over the 12 years to 1992 , despite several preventive strategies being introduced (including helmet wearing promotions and bicycle education courses). These results emphasise the need for additional strategies such as separating bicycles from cars, cycling proficiency tests, and bicycle inspections. Another recently suggested strategy is the certification of 'safe routes' for travel to school. ${ }^{14}$

As in most injury studies, boys were three times more likely than girls to sustain a bicycle related injury..$^{15}$ However, the injury rate of $294.7 / 100000$ children and fatality rate of $1 \cdot 8 / 100000$ boys due to bicycle trauma is higher than in other studies that included adults. ${ }^{16}$ Thompson $e t$ al found the 5-9 years old group to be at greater risk, ${ }^{17}$ whereas in our study the highest rates, both of injuries and deaths, occurred in 12 to 14 year olds. 
Other studies describing road related bicycle trauma have emphasised injuries arising on the road. ${ }^{1819}$ We investigated all bicycle related injuries and found no difference in non-fatal injury rates between those injured on and off the road. It is alarming to discover that children less than 4 years of age are riding two wheeled bicycles and being injured on the road. Previous authors have criticised bicycle riding on public roads by children less than 10 years of age. ${ }^{2021}$ Our findings not only reinforce that view, but also emphasise the vulnerability of very young children who ride bicycles in any location.

The hours between 3 and $6 \mathrm{pm}$ were consistently the most dangerous time. During these hours children were twice as likely to be injured on a non-school day than on a school day, suggesting that it is not just the trip home from school that is the problem. Possible explanations for the concentration between these hours include the youthful enthusiasm of children leaving school, group behaviour, and fatigue. Nevertheless incorporating preventive endeavours into the school curriculum may be beneficial.

The majority of children simply 'fell off' their bike, and were injured when they hit the ground. Our results clearly demonstrate that the greatest threat to children on bikes is cycling proficiency. It is notable how few injured cyclists were hit by moving vehicles, despite the most severe injuries and fatality resulting from these. Supervised bicycle proficiency training is suggested as a preventive approach, although the results of such measures are not yet clear. The Queensland Department of Transport runs 'BIKE ED' courses, but they are poorly subscribed. This same organisation advocates 'targeting specific groups for education via publicity and media resources'.22

Because 78 children identified a faulty bicycle as the cause of their incident, proper maintenance should be emphasised as a safety measure.

The number of children riding bicycles without wearing a helmet is exemplified by our data, particularly as there are still more children who present to general practitioners with head injuries not necessitating hospital attendance. The long term sequelae of severe brain injury may be serious or disabling. Even socalled 'minor' head injuries without loss of consciousness may have long term consequences. ${ }^{23}$ None of the children with a severe head injury had been wearing a helmet at the time of impact.

We reported in a previous paper that cycle helmets meeting the current Australian Standard reduce the relative risk of injuring the head in the kind of incident most child riders experience. ${ }^{3}$ However, because 315 children suffered facial injury, faces are obviously not adequately protected, and while facial injury per se is rarely life threatening, it can be disfiguring. ${ }^{24}$ Hence there is a need for research into helmet design to provide facial as well as head protection.

The severity of blunt abdominal trauma in children should not be underestimated and is not properly assessed by the paediatric trauma score. ${ }^{12}$ All with severe injuries struck unpadded metal handlebar ends. Prevention of these injuries lies in a change in handlebar design or added protection of existing handlebars.

Helmet wearing has been compulsory in Queensland since 1991, and an increase in wearing rate from $53 \%$ to $86 \%$ has been documented in primary schoolchildren. ${ }^{13}$ Our earlier report described the reduced rate of head injury and concussion associated with helmet wearing. ${ }^{3}$ Legislation for compulsory helmet wearing, and resources to ensure that this is enforced, appears to be a fundamental preventive strategy. Such an approach still has its opponents.

There are factors other than helmet wearing that have contributed to the reduction in head injury rates. Some reduction in head injury frequency occurred in Brisbane before the widespread use of protective helmets, but the reasons for this are not clear. ${ }^{25}$ None the less, our study emphasises the need for children to wear helmets at all times, whether riding on or off the road.

\section{Summary - preventive implications}

Children's cycling incidents are ubiquitous and frequent. As well as the enforcement of laws for compulsory helmet wearing, other preventive strategies include courses in cycling proficiency and bicycle maintenance, padding or modified design of handlebars, research into helmet design to provide facial protection, and publicity campaigns to educate parents about the importance of bicycle injuries.

The authors are indebted to the Federal Office of Road Safety Department of Transport and Communications, for financial assistance. They are most grateful to Joanne Lansbury and assistance. They are most grateful to Joanne Lansbury and Royal Children's and Mater Misericordiae Children's Hospitals Emergency Departments for cooperating in the study. Dr S Emergency Departments for cooperating in the study. Dr S Thomas was supported by the

The advice and encouragement given by Professor J Pearn is most gratefully acknowledged.

1 Pitt WR, Balanda KP, Nixon J. Child injury in Brisban South 1985-1991: implications for future injury surveillance. $\mathcal{F}$ Paediatr Child Health 1994; 30: 114-22.

2 Thompson RS, Rivara FP, Thompson DC. Case contro study of the effectiveness of bicycle helmets. N Engl $₹$ Med 1989; 320: 1361-7.

3 Thomas S, Acton C, Nixon J, Battistutta D, Pitt WR, Clark R. Effectiveness of bicycle helmets in preventing head injury in children. BMY 1994; 308: 173-6.

4 McDermott FT, Lane JC, Brazenor GA, Debney E. The effectiveness of bicyclist helmets: a study of 1710 casualeffectiveness of bicyclist helmets: a

5 Cass DT, Gray AJ. Paediatric bicycle injuries. Aust $N Z \mathscr{F}$ Surg 1989; 59: 719-22.

6 Teasdale G, Jennett B. Assessment of coma and impaired consciousness. A practical scale. Lancet 1974; ii: 81-4.

7 Tepas JJ, Mollitt DL, Talbert JL, Bryant M. The pediatric trauma score as a predictor of injury severity in the injured child. F Pediatr Surg 1987; 22: 14-8.

8 Australian Bureau of Statistics (Queensland Office). Census of population and housing. Catalogue No 2456.0, 2481.0. Brisbane: Australian Bureau of Statistics, June 1986, August 1991.

9 Australian Standard. Lightweight protective helmets (for use in pedal cycling, horse-riding and other activities requiring similar protection. No 2063.1. Sydney: Standards Associotion of Australia, 1989.

10 Williams M. Evaluation of the penetration test for bicyclists helmets. Comparative perfo helmets. Comparative performance of hard shell and foam helmets. Accid Anal Prev 1990; 22: 315-25. 11 Williams M. The protective performance of bicyclists 
12 Acton C, Thomas S, Clark R, Pitt WR, Nixon J, Leditschke JF. Abdominal injury due to handlebars. Med $\mathcal{f}$ Aust 1994; 160: $344-6$

13 Dix W, Dreves M. Six months review of compulsory helmet wearing. Report to the Road Users' Safety Branch, Road Safety Division, Queensland Department of Transport. Brisbane: Queensland Government, 1992.

14 Bergman AB, Rivara FP. Sweden's experience in reducing childhood injuries. Pediatrics 1991; 88: 69-74

15 Ginsburg HJ, Miller SM. Sex differences in children's risk taking behaviour. Child Dev 1982; 53: 426-8.

16 Krause JF, Fife D, Conroy C. Incidence, severity and outcomes of brain injuries involving bicycles. Am $\mathcal{F}$ Public Health 1987; 77: 76-9.

17 Thompson D, Thompson R, Rivara F. Incidence of bicycle related injuries in a defined population. Am $\mathcal{f}$ Public Health 1990; 80: 1388-90.

18 Spaite D, Murphy M, Criss E, Valenzuela T, Meislin H. A prospective analysis of injury severity among helmeted and non-helmeted cyclists involved in collisions with motor vehicles. 7 Trauma 1991; 31: 1510-6.

19 McCarthy M. Pedal cyclists, crash helmets and risk. Public Health 1991; 105: 327-34.

20 Nixon J, Clacher R, Pearn J, Corcoran A. Bicycle accidents in childhood. $B M \mathcal{H} 1987 ; 294: 1267-9$.

21 Simpson AHR, Unwin PS, Nelson IW. Head injuries, helmets, cycle-lanes and cyclists. BMF 1988; 296: $1161-2$.

22 King MH. Bicycle helmet legislation and enforcement in Queensland 1991-1993. Queensland Department of Transport. Brisband: Queensland Government, 1993.

23 Wagstyle T, Sutcliffe AJ, Alpar EK. Early prediction of outcome following head injury in children. $\mathcal{F}$ Pediatr Surg 1987; 22: 127-9.

24 Haug RH, Prather J, Indresano AT. An epidemiologic survey of facial fractures and concurrent injuries. $₹$ Oral Maxillofac Surg 1990; 48: 926.

25 Pitt WR, Thomas S, Nixon J, Clark R, Battistutta D, Acton $C$. Trends in head injuries among child bicyclists. $B M F$ 1994; 308: 177.

An introduction to the family-uncles and aunts, cousins, and friends

When I was young, my bedtime prayers concluded with a blessing for uncles and aunts, cousins, and friends, so it seemed a good idea to introduce newcomers to our rapidly growing family, friends, and neighbours. What follows is a list, almost certainly incomplete, of the major injury prevention organizations whose focus is on children and adolescents.

- Child Accident Prevention Trust (UK)

- SAFE KIDS (US)

- Safe Kids (NZ)

- Safe Kids (Canada)

- Children's Safety Network (US)

- Child Accident Prevention Foundation of Australia (Kidsafe)

- Child Accident Prevention Foundation of South Africa

- Ambulatory Pediatric Association Injury Control Special Interest Group

- Canadian Children's Safety Network (Canada)

- Injury Prevention Research Unit (Otago, NZ)

- Injury Prevention Foundation (Canada)

- National Injury Surveillance Unit (Australia)

I urge readers who know of organizations that have been omitted, to apologize on my behalf, and write with the details.

The following are routine newsletters put out by various groups that deal with injury prevention. Some are free; others not.

- Child Safety Review (Child Accident Prevention Trust, UK)

- Campaign Update (National SAFE KIDS Campaign, US)

- La Lettre de Securite Routiere (Societe de l'Assurance Automobile du Quebec)

- Safe Community News (WHO Collaborating Centre on Community Health Promotion, Karolinska Institute, S-127 83 Sundbyberg, Sweden)

- Status Report (Insurance Institute for Highway Safety, 1005 North Glebe Road, Arlington, VA 22201)

- Child Health (Canadian Institute for Child Health, 55 Parkdale, Ottawa, Ontario K1Y 1E5)

- Australian Injury Prevention Bulletin

- Hazard (Victorian Injury Surveillance System) (Monash, Australia)

- Child Safety News, Child Safety Centre (Royal Children's Hospital, Parkville, Australia)

There are certainly many others not listed; please send details, including cost, if any. 